\title{
Investigating Performance of Various Natural Computing Algorithms
}

\author{
Bharat V. Chawda \\ Ph.D. Research Scholar, Gujarat Technological University, Ahmedabad, Gujarat, India \\ E-mail: bharat.bbit@gmail.com \\ Dr. Jayeshkumar Madhubhai Patel \\ Associate Professor, MCA Programme, Ganpat University, Kherva, Gujarat, India \\ E-mail: jayeshpatel_mca@yahoo.com
}

\begin{abstract}
Nature is there since millenniums. Natural elements have withstood harsh complexities since years and have proved their efficiency in tackling them. This aspect has inspired many researchers to design algorithms based on phenomena in the natural world since the last couple of decades. Such algorithms are known as natural computing algorithms or nature inspired algorithms. These algorithms have established their ability to solve a large number of real-world complex problems by providing optimal solutions within the reasonable time duration. This paper presents an investigation by assessing the performance of some of the well-known natural computing algorithms with their variations. These algorithms include Genetic Algorithms, Ant Colony Optimization, River Formation Dynamics, Firefly Algorithm and Cuckoo Search. The Traveling Salesman Problem is used here as a test bed problem for performance evaluation of these algorithms. It is a kind of combinatorial optimization problem and known as one the most famous NP-Hard problems. It is simple and easy to understand, but at the same time, very difficult to find the optimal solution in a reasonable time - particularly with the increase in a number of cities. The source code for the above natural computing algorithms is developed in MATLAB R2015b and applied on several TSP instances given in TSPLIB library. Results obtained are analyzed based on various criteria such as tour length, required iterations, convergence time and quality of solutions. Conclusions derived from this analysis help to establish the superiority of Firefly Algorithms over the other algorithms in comparative terms.
\end{abstract}

Index Terms-Natural Computing Algorithms, Nature Inspired Algorithms, Traveling Salesman Problem, Genetic Algorithm, Ant Colony Optimization, River Formation Dynamics, Firefly Algorithm, Cuckoo Search.

\section{INTRODUCTION}

Nature is the best teacher. It has successfully provided extraordinary solutions to a large number of real-world complex problems by applying very simple approaches in systematic manners. This has attracted many researchers to mimic the nature in technology. As a result, natural computing has come up as a new era in the field of computing encompassing a broad range of applications. In the recent years, natural computing has established itself as an eminent force in finding promising solutions for complicated real world problems.

Natural computing algorithms are computer algorithms whose design draws inspiration from phenomena in the natural world [1]. These algorithms are also referred as nature-inspired algorithms, bio-inspired algorithms or clever algorithms. Two prime aspects of any natural computing algorithm are: exploration and exploitation [2] Exploration refers to generating diverse solutions to explore search space as broadly as possible. It helps to avoid local minima. Exploitation refers to improving the quality of generated solutions by applying local search or other means. It strives to find the best solution. Natural computing algorithms work in an iterative manner by exploring and exploiting search space iteration by iteration to find optimal solutions.

The success of natural computing algorithms and their acceptance among researchers is mainly due to four factors as described in [3]. These algorithms are simple as they use simple concepts derived from nature. They are flexible and can be applied to different problems without major structural changes in the algorithm. They use derivation-free mechanisms and have abilities to avoid local optima (or, minima). These features provide them superiority over traditional algorithms such as exact methods involving logical or mathematical programming.

Contrast to this, according to No Free Lunch (NFL) theorem [4], no single natural computing algorithm is best suited for solving all optimization problems. This has pushed researchers to develop new algorithms as well as to enhance existing algorithms. As a result, a number of various natural computing algorithms and their variations have been developed over the last couple of decades. These algorithms are summarized in next section.

This paper concentrates on some of the well known natural computing algorithms along with their variations such as Genetic Algorithm (GA), Ant Colony Optimization (ACO), River Formation Dynamics (RFD), Firefly Algorithm (FA) and Cuckoo Search (CS). The performance of these algorithms is investigated by applying them to the Traveling Salesman Problem (TSP) 
which belongs to the class of NP-hard problems.

The remainder of this paper is organized as follows: Section II summarizes natural computing algorithms. Section III discusses the Traveling Salesman Problem along with its mathematical definition and associated complexity. Section IV describes various natural computing algorithms and their adaptations to solve TSP. Section V presents the detailed results of experiments conducted on a set of benchmark TSP instances given in TSPLIB library [5]. Finally, section VI provides conclusions based on comparative analysis of various algorithms.

\section{SUMmary OF NATURAL COMPUTING AlgORITHMS}

This section summarizes various natural computing algorithms as given in table 1. Various algorithms are listed along with their abbreviations, inspirational natural phenomena, names of researchers and year of publication.

An honest attempt has been made in this section to provide state-of-the-art sum-up information on natural computing algorithms. This summary is aimed to provide readers a comprehensive list of all natural computing algorithms, developed in as early as the 1970s to recent ones, and to inspire them for further research.

Table 1. Natural Computing Algorithms - A Summary

\begin{tabular}{|c|c|c|c|c|c|}
\hline Abbreviation & Algorithm & Underlying Natural Phenomena & Author(s) & Year & Reference(s) \\
\hline GA & Genetic Algorithm & $\begin{array}{l}\text { Natural selection process that mimics biological } \\
\text { evolution }\end{array}$ & Holland & $\begin{array}{l}1973 \\
1975 \\
1992\end{array}$ & {$[6]-[8]$} \\
\hline SA & Simulated Annealing & Cooling process of molten metal & $\begin{array}{l}\text { Kirkpatrick, Gelatt, } \\
\text { Vecchi }\end{array}$ & $\begin{array}{l}1983 \\
1997\end{array}$ & [9], [10] \\
\hline MA & Memetic Algorithm & Cultural revolution & Moscato & 1989 & [11] \\
\hline $\mathrm{ACO}$ & Ant Colony Optimization & Foraging behavior of ants & Dorigo, Colorni & 1991 & {$[12]$} \\
\hline GP & Genetic Programming & $\begin{array}{l}\text { Extension of GA - Solution is represented as a tree } \\
\text { with variable length }\end{array}$ & Koza & 1992 & {$[13]$} \\
\hline PSO & Particle Swarm Optimization & Flocking behavior of birds & Kennedy, Eberhart & 1995 & {$[14]$} \\
\hline $\mathrm{DE}$ & Differential Evolution & $\begin{array}{l}\text { Genetic evolution with mutation as an arithmetic } \\
\text { combination of individuals }\end{array}$ & Storn, Price & 1997 & {$[15]$} \\
\hline BEA & $\begin{array}{l}\text { Bacterial Evolutionary } \\
\text { Algorithm }\end{array}$ & $\begin{array}{l}\text { Microbial evolution phenomenon along with gene } \\
\text { transfer operation }\end{array}$ & Nawa, Furuhashi & 1999 & [16] \\
\hline AIS & Artificial Immune System & Human immune system & Dasgupta & $\begin{array}{l}1999 \\
2003\end{array}$ & {$[17][18]$} \\
\hline ES & Evolution Strategies & Adaption and evolution by means of natural selection & Beyer, Schewefel & 2002 & [19] \\
\hline $\mathrm{BFO}$ & Bacterial Foraging Optimization & Foraging behavior of bacteria & Passino & 2002 & {$[20]$} \\
\hline FSA & Fish Swarm Algorithm & Schooling behavior of fish & Li, Shao, Qian & 2003 & [21] \\
\hline SFLA & $\begin{array}{l}\text { Shuffled Frog Leaping } \\
\text { Algorithm }\end{array}$ & Frog leaping on stones in a pond & Eusuff, Lansey & $\begin{array}{l}2003 \\
2006\end{array}$ & [22], [23] \\
\hline $\mathrm{SCO}$ & Social Cognitive Optimization & Human social cognition & Xie, Zhang & 2004 & {$[24]$} \\
\hline IWCO & $\begin{array}{l}\text { Invasive Weed Colony } \\
\text { Optimization }\end{array}$ & $\begin{array}{l}\text { Ecological process of weed colonization and } \\
\text { distribution }\end{array}$ & Mehrabian, Lucas & 2006 & {$[25]$} \\
\hline $\mathrm{ABC}$ & Artificial Bee Colony & Foraging behavior of bees & Karaboga, Basturk & $\begin{array}{l}2005 \\
2007\end{array}$ & {$[26],[27]$} \\
\hline GSO & Group Search Optimization & $\begin{array}{l}\text { Searching behavior of animals and their group living } \\
\text { theory }\end{array}$ & $\mathrm{He}, \mathrm{Wu}$, Saunders & 2006 & [28] \\
\hline $\mathrm{CFO}$ & Central Force Optimization & $\begin{array}{l}\text { Metaphor of the gravitational kinematics and particle } \\
\text { motion in a gravitational field }\end{array}$ & Formato & $\begin{array}{l}2007 \\
2008\end{array}$ & {$[29],[30]$} \\
\hline RFD & River Formation Dynamics & How rivers are formed & $\begin{array}{c}\text { Rabanal, Rodriguez, } \\
\text { Rubio }\end{array}$ & $\begin{array}{l}2007 \\
2009\end{array}$ & {$[31],[32]$} \\
\hline IWD & Intelligent Water Drops & Actions and reactions among water drop in a river & Shah-Hosseini & 2007 & {$[33]$} \\
\hline RIO & Roach Infestation Optimization & Social behavior of cockroaches & $\begin{array}{l}\text { Havens, Spain, } \\
\text { Salmon, Keller }\end{array}$ & 2008 & {$[34]$} \\
\hline MS & Monkey Search & Mountain climbing process of monkeys & Zhao, Tang & 2008 & {$[35]$} \\
\hline $\mathrm{BBO}$ & $\begin{array}{l}\text { Biogeography-Based } \\
\text { Optimization }\end{array}$ & Distribution of species in nature over time and space & Simon & 2008 & [36] \\
\hline LCA & $\begin{array}{l}\text { League Championship } \\
\text { Algorithm }\end{array}$ & Competition of sport teams in a league championship & Kashan & 2009 & [37] \\
\hline GSO & Glowworm Swarm Optimization & $\begin{array}{l}\text { Behavior of glowworms - capability to change } \\
\text { intensity of luciferin emission }\end{array}$ & Krishnanand, Ghose & 2009 & {$[38]$} \\
\hline BBMO & Bumble Bees Mating & Mating behavior of bumble bees & Marinakis, Marinaki, & 2009 & {$[39]$} \\
\hline
\end{tabular}




\begin{tabular}{|c|c|c|c|c|c|}
\hline & Optimization & & Matsatsinis & & \\
\hline $\mathrm{HSO}$ & Hunting Search Optimization & $\begin{array}{l}\text { Group hunting behavior of animals such as lions and } \\
\text { wolves }\end{array}$ & Oftadeh, Mahjoob & 2009 & [40] \\
\hline FA & Firefly Algorithm & Flashing behavior of fireflies & Yang & 2009 & [41] \\
\hline HS & Harmony Search & Improvisation process of musicians & Yang & 2009 & [42] \\
\hline PFA & Paddy Field Algorithm & Reproduction of plant populations & $\begin{array}{c}\text { Premaratne, } \\
\text { Samarabandu, Sidhu }\end{array}$ & 2009 & [43] \\
\hline GSA & Gravitational Search Algorithm & Low of gravity and resultant mass interactions & $\begin{array}{l}\text { Rashedi, } \\
\text { Nezamabadi-Pour, } \\
\text { Saryazdi }\end{array}$ & 2009 & [44] \\
\hline CS & Cuckoo Search & $\begin{array}{l}\text { Breeding behavior of cuckoo - laying color-pattern } \\
\text { mimicked eggs in nests of other birds }\end{array}$ & Yang, Deb & $\begin{array}{l}2009 \\
2010\end{array}$ & {$[45],[46]$} \\
\hline BIA & Bat Inspired Approach & Echolocation behavior of bats & Yang & 2010 & [47] \\
\hline FA & Fireworks Algorithm & $\begin{array}{l}\text { Explosion processes of fireworks and mechanisms } \\
\text { for maintaining diversity of sparks }\end{array}$ & Tan, Zho & 2010 & [48] \\
\hline PPA & Plant Propagation Algorithm & $\begin{array}{l}\text { Propagation of the plants, particularly Strawberry } \\
\text { plants }\end{array}$ & Salhi, Fraga & 2011 & [49] \\
\hline $\mathrm{CAB}$ & Collective Animal Behavior & $\begin{array}{l}\text { Collective behavior of different animal groups such } \\
\text { as swarming, milling, migrating in aligned groups }\end{array}$ & $\begin{array}{l}\text { Cuevas, González, } \\
\text { Zaldivar, Pérez- } \\
\text { Cisneros, García }\end{array}$ & 2012 & [50] \\
\hline WCA & Water Cycle Algorithm & $\begin{array}{l}\text { Real world water cycle among } \\
\text { transpiration/evaporation, condensation, precipitation }\end{array}$ & $\begin{array}{c}\text { Eskandar, Sadollah, } \\
\text { Bahreininejad, } \\
\text { Hamdi }\end{array}$ & 2012 & [51] \\
\hline $\mathrm{KH}$ & Krill Herd & Herding behavior of krill individuals & Gandomi, Alavi & 2012 & [52] \\
\hline $\mathrm{BCO}$ & Bacterial Colony Optimization & $\begin{array}{l}\text { Behavior of E. Coli bacteria at different development } \\
\text { stages in their life cycle }\end{array}$ & Niu, Wang & 2012 & [53] \\
\hline LA & Lion's Algorithm & $\begin{array}{l}\text { Social behavior of lions that helps to keep } \\
\text { themselves strong }\end{array}$ & Rajakumar & 2012 & [54] \\
\hline $\mathrm{SCO}$ & Stem Cells Optimization & Reproduction behavior of stem cells & $\begin{array}{l}\text { Taherdangkoo, } \\
\text { Yazdi, Bagheri }\end{array}$ & 2012 & [55] \\
\hline BNMR & $\begin{array}{l}\text { Blind Naked Mole-Rats } \\
\text { Algorithm }\end{array}$ & Social behavior of Mole-Rats & Shirzadi, Bagheri & 2012 & [56] \\
\hline FPA & Flower Pollination Algorithm & Fertilization/Pollination process of flowers & Yang & $\begin{array}{l}2012 \\
2014\end{array}$ & [57], [58] \\
\hline $\mathrm{BH}$ & Black Hole & Star swallowing behavior of black holes & Hatamlou & 2013 & [59] \\
\hline $\mathrm{CA}$ & Cuttlefish Algorithm & $\begin{array}{l}\text { Mechanism of color changing behavior adopted by } \\
\text { the cuttlefish }\end{array}$ & $\begin{array}{l}\text { Eesa, Abdulazeez, } \\
\text { Orman }\end{array}$ & 2013 & {$[60]$} \\
\hline MBA & Mine Blast Algorithm & Concept of mine bomb explosion & $\begin{array}{c}\text { Sadollah, } \\
\text { Bahreininejad, } \\
\text { Eskandar, Hamdi }\end{array}$ & 2013 & [61] \\
\hline SSO & Social Spider Optimization & Simulation of cooperative behavior of social spiders & $\begin{array}{l}\text { Cuevas, Cienfuegos, } \\
\text { Zaldívar, Pérez- } \\
\text { Cisneros }\end{array}$ & 2013 & [62] \\
\hline SMO & Spider Monkey Optimization & $\begin{array}{l}\text { Foraging behavior of spider monkeys based on } \\
\text { fission-fusion }\end{array}$ & $\begin{array}{l}\text { Bansal, Sharma, } \\
\text { Jadon, Clerc }\end{array}$ & 2014 & [63] \\
\hline AMO & Animal Migration Optimization & $\begin{array}{l}\text { Behavior of animals during migration from one } \\
\text { location to another location }\end{array}$ & Li, Zhang, Yin & 2014 & [64] \\
\hline BMO & Bird Mating Optimizer & Mating strategies of birds & Askarzadeh & 2014 & [65] \\
\hline FOA & Forest Optimization Algorithm & Seeding procedure of the trees in a forest & $\begin{array}{l}\text { Ghaemi, Feizi- } \\
\text { Derakhshi }\end{array}$ & 2014 & [66] \\
\hline GWO & Grey Wolf Optimizer & $\begin{array}{l}\text { The leadership hierarchy and hunting mechanism of } \\
\text { grey wolves }\end{array}$ & $\begin{array}{l}\text { Mirjalili, Mirjalili, } \\
\text { Lewis }\end{array}$ & 2014 & [3] \\
\hline VSA & Vortex Search Algorithm & $\begin{array}{l}\text { Vortex (swirl) pattern due to vertical flow of affected } \\
\text { fluids }\end{array}$ & Doğan, Ölmez & 2015 & [67] \\
\hline Wwo & Water Wave Optimization & $\begin{array}{l}\text { Propagation, refraction and breaking phenomena of } \\
\text { shallow water waves }\end{array}$ & Zheng & 2015 & [68] \\
\hline $\mathrm{EHO}$ & Elephant Herding Optimization & Herding behavior of elephant groups & Gai-Ge Wang & 2015 & [69] \\
\hline RRO & Raven Roosting Optimization & $\begin{array}{l}\text { Social roosting and foraging behavior of common } \\
\text { raven }\end{array}$ & $\begin{array}{l}\text { Brabazon, Cui, } \\
\text { O'Neill }\end{array}$ & 2016 & [70] \\
\hline
\end{tabular}




\section{TRAVELING SALESMAN PROBLEM}

Optimization strives to find the best solution from all feasible solutions. Optimization problem can be either continuous or discrete [71], [72]. Continuous optimization problems contain variables that can take on real values, such as, solving polynomial equations. In contrast to this, discrete optimization problems, also known as combinatorial optimization problems, contain variables that can take on integer values, such as, the Traveling Salesman Problem.

The Traveling Salesman Problem (TSP) [73]-[75] is one of the most widely studied problems in the arena of discrete combinatorial optimization problems. The basic concept of the TSP is to find a closed tour of a given number of cities, visiting each city exactly once and returning to the starting city, by minimizing the length of the tour.

In mathematical terms, the TSP can be defined as:

- Given a weighted graph $G=(V, E)$, where $V$ is a set of cities and $E$ is a set of edges between cities,

- find the tour of all cities that has the minimum total cost, or in other words,

- minimize $f(x)=\sum_{i=1}^{n} w_{\mathrm{i}, \mathrm{i}+1}$ where $n$ is a total number of cities and $w_{i, i+1}$ represents distance between city $i$ and its next city in a tour.

With the increase in problem size (number of cities), the total number of possible tours increases exponentially in terms of $n$ ! This complexity brings the TSP under the category of an NP-hard combinatorial optimization problem and makes it infeasible to find optimal solution using traditional methods.

The TSP can be either Symmetric or Asymmetric. In the Symmetric TSP, the distance between any two cities is same from either side, while in Asymmetric TSP, this distance is not same. As the back and forth tours are same for the Symmetric TSP, a total number of tours can be given by $(n-1) ! / 2$.

The positive point of the TSP is its simplicity and easiness in understanding. This prevents the behavior of the algorithm, used to solve the TSP, from being obscured by too many technicalities. Due to this reason, the TSP is used as the test-bed problem in this paper to assess the performance of algorithms discussed later.

\section{NATURAL COMPUTING AND TSP}

Careful examination of the natural computing algorithms shows that most of them, particularly recently developed ones, are more inclined towards continuous optimization problems. There are mainly two reasons behind this. First, it is relatively easy to solve continuous optimization problems. Second, it is also easy to map continuous optimization problems with natural phenomena. In contrast to this, discrete or combinatorial optimization problems are difficult to solve and same applies to their mapping with natural phenomena.

In this section, five different natural computing algorithms are described along with their pseudo code, adaptation to solve the TSP and parameters used.

\section{A. Genetic Algorithm}

Genetic Algorithm (GA), proposed and explored in [6]-[8], has been inspired by Darwin's theory of evolution, mimicking the process of natural selection for survival of the fittest individual. GA is a populationbased natural computing algorithm that applies various operators such as Selection, Crossover and Mutation to solutions in a population to generate next generation. Three important points to be considered while applying GA to solve any problem are: First, a probable solution must be represented in such a way that it can be encoded on a GA chromosome. Second, each solution must have some fitness function to evaluate it. Third, various operators and parameters must be determined. Important parameters affecting the performance of GA are population size, crossover rate, mutation rate and a number of generation.

- Pseudo code:

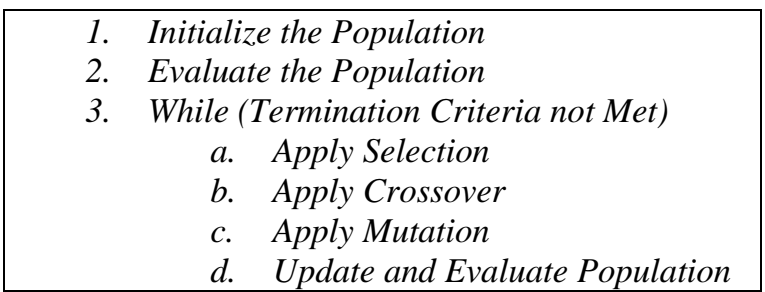

A population is a set of solutions (chromosomes). Random solutions are generated to initialize a population according to given population size. Each solution is evaluated based on an assigned fitness value. Termination criteria can be predefined a number of generations, maximum allowed time duration or stagnations in the result.

Selection is used to replace worse solutions with better solutions. Crossover is used to generate new offspring by combining genes of selected solutions. Mutation is used to generate new offspring by randomly changing genes of an individual solution. Each solution in a population is evaluated. This process continues until some convergence criterion meets.

Different mechanisms used for selection, crossover and mutation have been explained in [76]. According to it, popular selection mechanisms are - truncation selection, tournament selection, reward based selection, roulette wheel selection (fitness proportionate selection) and rank selection. Popular crossover mechanisms are - k-point crossover, uniform crossover, uniform order-based crossover, order-based crossover, partially matched crossover (PMX) and cycle crossover (CX). Common mutation mechanisms are bit-flip and swap genes.

\section{- Adapting GA to TSP:}

GA has been adapted to solve random TSP in [77]. Similar to that approach, a solution (or, tour) is encoded as a random permutation for cities starting from 1 to $\mathrm{N}$. Tour length is considered as a fitness value and GA 
attempts to minimize the tour length in each generation. Tournament selection is used as a selection operator which selects and duplicates better tour between two randomly selected tours. Partially matched crossover is used as a crossover operator as given in [76]. Mutation operator flips cities between randomly selected two points in a tour. Generated tours are evaluated against their tour lengths and the population is updated. This process continues until stagnation occurs in the best tour of the population.

\section{- Parameters Used:}

Total number of cities $=\mathrm{N}$, population size $=64$, crossover rate $=1.0$, mutation rate $=0.4$, stagnation counter $=\mathrm{N}$.

\section{B. Ant Colony Optimization}

Ant Colony Optimization (ACO), proposed in [12] and explored in [78], has been inspired by the foraging behavior of real ants. Ants possess natural ability to find the shortest tour between the food source and their nest. Ants deposit a fixed amount of pheromone while Traveling from their nest to food source and vice versa. Initially, they move randomly. An ant having shorter tour will return earlier increasing pheromone value on that tour. Other ants will prefer a tour with higher pheromone value to travel. This results in more and more ants following shorter tour further increasing pheromone value on that tour. In contrast to this, longer tours possess less movement of ants comparatively and so less pheromone value. Also, the pheromone evaporates by a certain amount at a fixed stable rate. These results in the elimination of longer tours after some time and all ants follow the shortest possible tour.

This behavior of ants is modeled mathematically in ACO. This algorithm progresses in an iterative manner. With each iteration, all ants construct their own tour initially randomly or based on some heuristic value, and later, based on pheromone values on available tours in combination with heuristic values. New pheromone is deposited on tours found by each ant. Also, some pheromone is evaporated from each possible tour. This process continues until convergence occurs, or in other words, all ants follow single tour - probably the shortest one.

In ACO, the pheromone is deposited on tours found by each ant in inverse proportions to their tour length, i.e. depositing more pheromone on better tours and vice versa. In Elitist ACO [78], an extra amount of pheromone is deposited on best tour to increase the chance of selecting that tour by ants in next iteration. The modified Elitist ACO, which is implemented here, deposits pheromone only on the best tour. This results in a faster convergence of the solutions.

- Pseudo code for modified Elitist ACO:

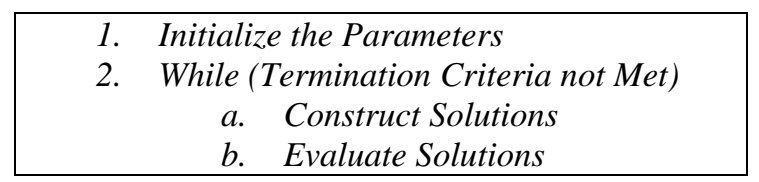

\begin{tabular}{|l}
\hline c. $\begin{array}{l}\text { Deposit Pheromone on best } \\
\text { tour only } \\
\text { Evaporate Pheromone }\end{array}$ \\
\hline
\end{tabular}

All problems need to be converted to graphs to apply ACO. If a problem fulfills this criterion, the given algorithm starts with initializing various parameters such as a total number of ants $(\mathrm{M})$, pheromone matrix $(\tau)$, heuristic information matrix $(\eta)$, evaporation rate $(\rho), \alpha$ and $\beta$. Generally, $M$ is kept same as that of a total number of nodes. Each ant is put on the randomly selected node (or city, in the case of TSP).

After initialization, iterative process of algorithm starts. Each ant constructs its own tour (or solution). Once all ants construct their tours, these tours are evaluated according to their fitness function to find the best tour. In next step, the pheromone is updated by evaporating it from all tours and depositing it on the best tour. This process continues until stagnation occurs in the best tour or some other criteria such as predefined maximum iterations or time duration meets.

\section{- Adapting modified Elitist ACO to TSP:}

The TSP can be easily considered as a graph having each city as a node and a path between two cities as an arc (or edge) between two nodes. To apply modified Elitist ACO to TSP, various parameters are initialized. Pheromone matrix $(\tau)$ is initially given unique constant value. During the iterative process of the algorithm, ants construct their own tour. A probabilistic mechanism is used to select next city to be visited from the current city by each ant. Suppose an ant $k$ is currently on city $i$. It selects next city $j$ to visit based on the probability given by

$$
p_{i j}^{k}=\left(\tau_{i j}\right)^{\alpha}\left(\eta_{i j}\right)^{\beta}
$$

Where, $\boldsymbol{\tau}_{\boldsymbol{i} \boldsymbol{j}}$ and $\boldsymbol{\eta}_{\boldsymbol{i j}}$ represents pheromone value and inverse distance between city $i$ and city $j$ respectively. $\alpha$ and $\beta$ are constant parameters used to control the relative importance of the pheromone values $(\tau)$ and the heuristic information $(\eta)$. As in symmetric TSP any city can be visited from a given city, equation (1) is modified from that of given in [79], [80]. A roulette wheel selection is applied to determine city $j$ based on available probabilities.

Once all ants construct their tours, these tours are evaluated in terms of tour length to find the best tour. In next step, the pheromone is updated by evaporating it from all tours and depositing on the best tour. Pheromone evaporation is performed according to the following equation.

$$
\tau_{i j} \leftarrow(1-\rho) \tau_{i j}
$$

where $\rho$ is the evaporation rate.

Pheromone is deposited according to the following equation. 


$$
\tau_{i j} \leftarrow \tau_{i j}+1 / \mathrm{C}
$$

where $C$ is the length of the best tour.

This process continues until stagnation occurs in the best tour.

\section{- Parameters Used:}

Total number of cities $=N$, total number of Ants $=N, \alpha$ $=1.0, \beta=5.0, \rho=0.5$, stagnation counter $=50$.

\section{River Formation Dynamics}

River Formation Dynamics (RFD), introduced in [31], is inspired based on how rivers are formed in nature. Water drops, constitutional elements of the river, flow down to the sea and transform the landscape. Drops erode the ground and decrease altitude while traversing high decreasing gradients. They also deposit carried sediments and increase altitude in flatter areas. Based on decrease or increase in altitudes of nodes, gradients are modified affecting movement of subsequent drops. In this way, decreasing gradients are formed. They represent the path from the source to the sea in the form of a river. These paths model the solutions for the problem under consideration.

- Pseudo code:

\begin{tabular}{|rl|}
\hline 1. & Initialize Drops \\
2. & Initialize Nodes \\
3. & While (Termination Criteria not Met) \\
& a. Move Drops \\
b. Erode Nodes \\
c. Deposit Sediments \\
d. Analyze Paths
\end{tabular}

Similar to ACO, all problems need to be converted to graphs to apply RFD. Mathematical model for the RFD has been elaborated in [31], [32], [81]. This algorithm begins by depositing all drops in the initial node. In next step, all nodes of the graph are initialized by assigning them certain altitudes. A destination node is assigned altitude zero. This node represents a sea. The altitude of all other nodes is set to some equal positive value.

After initialization, iterative process of algorithm starts. Drops are moved based on the altitude difference and distance between two nodes. Based on the movement of drops, nodes are eroded and sediments are deposited. The resultant paths are evaluated in terms of the fitness function. This process continues until stagnation occurs in the best solution, i.e. all drops follow the same path, or some other criteria such as predefined maximum iterations or time duration meet.

Generally, drops move from higher altitude to lower one only. A variation of RFD, called Symmetric RFD (sRFD), is proposed and used in this paper. In symmetric RFD, drops are allowed to move in any direction.

\section{- Adapting Symmetric RFD to TSP:}

Adapting RFD to TSP is given in [81], [82]. A TSP is modeled as a graph having each city as a node and a path between two cities as an arc (or edge) between two nodes.
RFD is adapted here with some improvements.

Instead of depositing all drops to a single node, drops are deposited to randomly selected nodes to explore the entire search space in a fair manner.

All nodes are assigned same unique altitudes values. They are also eroded initially based on the distance between two nodes as given by the following equation.

$$
\begin{gathered}
\text { erosion }=1 / d_{i j} \\
\text { altitude }_{j}=\text { altitude }_{j}-\text { erosion }
\end{gathered}
$$

A probabilistic mechanism selects next node to be visited from the current node by each drop based on the decreasing gradient as given by the following equation.

$$
\operatorname{decGradient}_{i j}=\frac{\mid \text { altitude }_{j}-\text { altitude }_{i} \mid}{d_{i j}}
$$

The reason behind considering absolute value of the difference between two altitudes is symmetric TSP. For symmetric TSP, a tour in either direction is same. For example, two different tours A-B-C-D-A and A-D-C-B-A have no difference in the context of symmetric TSP. An absolute value of decreasing gradient allows a drop to move in any direction.

Erosion during movement of drops is directly proportional to decreasing gradient. Movement across nodes with high decreasing gradient cause more erosion and vice versa.

Continuous erosion may result in almost zero altitudes for all nodes after some iteration. To avoid this, the altitude of all nodes is slightly increased by depositing sediments after erosion process completes. The amount of sediment to be deposited is considered as average erosion across all nodes.

After updating altitudes, constructed paths by each drop are analyzed in terms of tour length to determine the best tour. This process continues until stagnation occurs in the best tour.

\section{- Parameters Used:}

Total number of cities $=\mathrm{N}$, total number of Drops $=\mathrm{N}$, stagnation counter $=\mathrm{N}$.

\section{Firefly Algorithm}

Firefly algorithm (FA), introduced in [41] and explored in [83], is inspired based on flashing behavior of fireflies. In formulating FA, three assumptions have been made: First, a firefly is unisexual and can be attracted by any other fireflies regardless of their sex. Second, attractiveness depends on their brightness and varies with distance. Less bright firefly is attracted by brighter one and so moves towards it. A firefly can move randomly if there is no other brighter firefly available. Third, the landscape of the objective function determines the brightness of a firefly. This algorithm models the quality of solution as a brightness of the firefly. A firefly with maximum brightness represents the best solution.

- Pseudo code: 


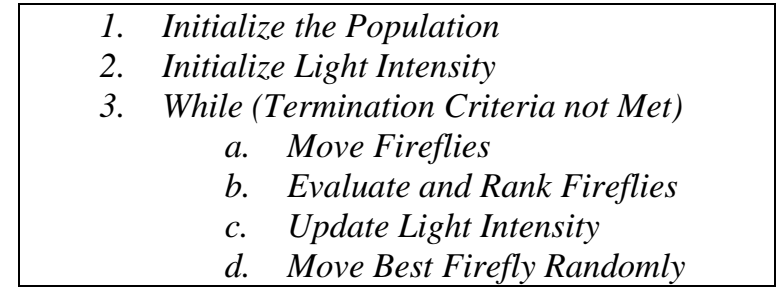

Each firefly represents one potential solution. A population is a set of solutions and initialized with randomly generated solutions. Each solution is evaluated against its fitness function and light intensity (or brightness) is assigned to each firefly based on the fitness value - better the fitness, better the brightness. Termination criteria for an iterative process can be predefined a number of generations, maximum allowed time duration or stagnations in the result.

In each iteration, a firefly is moved towards another firefly based on its attractiveness. A firefly's attractiveness is proportional to light intensity seen by other fireflies and can be given by

$$
\beta=\beta_{0} e^{-\gamma r^{2}}
$$

where $\beta_{0}$ is the attractiveness at the origin, $r$ is the distance between two fireflies and $\gamma$ is a fixed light absorption coefficient. $\beta_{0}$ is determined based on the fitness function.

Once movement of fireflies completes, they are evaluated and assigned ranks to determine the best firefly. Light intensity, $\beta_{0}$, is updated based on fitness values for each firefly. At the end, best firefly is allowed to move randomly to explore the search space. This process continues until some termination criteria occur.

A variation of FA, called improved FA (iFA), is proposed and used in this paper. Instead of only best firefly, this variation allows a fraction of better fireflies to move randomly.

\section{- Adapting Improved FA to TSP:}

FA has been adapted to solve TSP in [84], [85]. A solution (or, tour) is encoded as a random permutation for cities. Each firefly represents a single tour. A population is initialized with such randomly generated tours. The fitness of each tour is evaluated in terms of tour length. Light intensity, $\beta_{0}$, for each firefly is assigned as given by the following equation.

$$
\beta_{0}=\frac{1}{\text { tour length }}
$$

The movement of a firefly has been improved by allowing it to move towards only the best firefly in this paper. Number of steps taken for such movement is randomly selected between 2 and $\mathrm{d}_{\mathrm{ij}}$ as given by,

$$
\text { steps }=\operatorname{random}\left(2, d_{i j}\right)
$$

where, $\mathrm{d}_{\mathrm{ij}}$ is the hamming distance between two tours. During each step, firefly moves towards best firefly, i.e. best tour, using inversion mutation, improving its solution quality.

After moving fireflies, each tour is evaluated and light intensities of fireflies are updated. In addition, this adaptation allows top $20 \%$ fireflies to move randomly rather than a single best one as suggested in original algorithm. This helps to explore the search space in a better way as well as avoids local minima.

This process continues until stagnation occurs in the best tour.

\section{- Parameters Used:}

A total number of cities $=\mathrm{N}$, a total number of fireflies = either 10 or $\mathrm{N} / 4$, whichever is maximum, stagnation counter $=\mathrm{N}$.

\section{E. Cuckoo Search}

Cuckoo Search (CS), given in [45], [46], is inspired by breeding behavior of cuckoo - laying color-pattern mimicked eggs in nests of other birds. In formulating CS three main rules are idealized. First, each cuckoo lays one egg at a time and dumps it in a randomly chosen nest. The number of available host nests is fixed. Each nest (or egg) represents one potential solution. Second, the better nests with high-quality eggs will continue to next generation. Third, the host bird discovers an egg, laid by a Cuckoo, with a probability of $P_{a} \epsilon(0,1)$ from some set of worst nests. In this case, the host bird can either throw away this alien egg or simply abandon the nest and build a new nest.

\section{- Pseudo code:}

1. Initialize Population of ' $N$ ' Nests

2. Evaluate Nests

3. While (Termination Criteria not Met)

a. Randomly Generate New Solution $S_{i}$ from Best Nest

b. Randomly Choose Nest $S_{j}$ from Population

c. If $S_{i}$ is better than $S_{j}$ Replace $S_{j}$ with $S_{i}$

d. Abandon Worse Nests, Replace with Randomly Generated Nests

e. Evaluate Nests

Algorithm begins with initialization of a population with randomly generated solutions. Each solution is a nest (or an egg) and is evaluated against its fitness function to find out the best nest. Termination criteria for an iterative process can be predefined a number of generations, maximum allowed time duration or stagnations in the result.

In each iteration, new solutions are generated by applying random walk or levy flights to the best solution. If these solutions are better than randomly chosen solutions from the population, later ones are replaced. In proportion to given $P_{a}$, worse nests are abandoned and replaced with randomly generated solutions. The entire population is evaluated again to find out the best solution. This process continues until termination criteria meet. 


\section{- Adapting CS to TSP:}

CS has been adapted to solve spherical TSP in [86]. Similar to TSP, another problem is PCB Holes Drilling. CS has been adapted to solve this problem in [87].

To represent a random tour, as given in [87], a vector of random values between 0 and 1 is generated. For example, if total number of cities, $N=5$, then

$$
S=[0.9134,0.6324,0.0975,0.2785,0.5469]
$$

$\mathrm{S}$ is sorted in ascending order and the relative order of each of the values of $S$ is found. This relative order represents the sequence of cities in a tour as given below.

$$
\text { Sorted } S=[0.0975,0.2785,0.5469,0.6324,0.9134]
$$

So, city sequence in tour will be, $T=\left[\begin{array}{lllll}3 & 4 & 5 & 2 & 1\end{array}\right]$

A population of $N$ solutions is initialized by randomly generating a set of $N$ different $S$. Each solution is evaluated in terms of tour length and best solution is determined.

After this, in iterative process, a new solution is generated using equation,

$$
\text { new nest }=\text { best nest }+\alpha * \text { rand }
$$

where $\alpha$ is a constant value and rand represents random values between -1 and 1 .

If the new nest has a better tour, i.e. with shorter tour length, compared to randomly chosen nest from the population, the later one is replaced with a new nest.

From entire population, 20\% worse nests are abandoned and replaced with the randomly generated tour as given by the following equation.

$$
\text { new nest }=\text { worse nest }+\alpha * \text { rand }
$$

At the end of each iteration, the entire population is evaluated to determine the best solution. This process continues until stagnation occurs in the best tour.

\section{- Parameters Used:}

Total number of cities $=\mathrm{N}$, total number of nests $=\mathrm{N}$, $\alpha=0.1$, percentage of abandon $\left(P_{a}\right)=0.2$, stagnation counter $=\mathrm{N}$.

\section{RESULTS AND DISCUSSION}

Various natural computing algorithms - GA, modified elitist ACO, symmetric RFD, improved FA and CS have been applied to 8 different TSP instances given in TSPLIB [5] named burma14, ulysses22, eil51, eil76, kroa100, bier127, kroa150, and kroa200. The number in the instance identifier is the problem size in terms of a total number of cities, for example, burma14 has 14 cities. For a stopping criterion, stagnation in the best tour has been used. Derived results have been averaged over 10 different runs. Algorithms have been implemented using

\begin{tabular}{|c|c|c|c|c|c|}
\hline \multirow{2}{*}{$\begin{array}{c}\text { TSP } \\
\text { Instance }\end{array}$} & \multicolumn{3}{|c|}{ Tour Length } & \multirow{2}{*}{ Iteration } & \multirow{2}{*}{$\begin{array}{l}\text { Time } \\
\text { (Sec) }\end{array}$} \\
\hline & Best & Average & Worst & & \\
\hline burma14 & 3462.30 & 3490.59 & 3613.91 & 32.80 & 0.11 \\
\hline ulysses 22 & 6993.08 & 7078.62 & 7282.15 & 72.60 & 0.25 \\
\hline eil51 & 443.47 & 455.97 & 471.44 & 344.50 & 1.42 \\
\hline eil76 & 573.21 & 595.94 & 610.10 & 653.00 & 3.24 \\
\hline kroa100 & 22123.86 & 23422.65 & 25280.06 & 1189.00 & 6.90 \\
\hline bier127 & 123477.30 & 129260.90 & 135798.20 & 2448.60 & 16.91 \\
\hline kroa150 & 28181.29 & 29450.92 & 31623.33 & 2486.70 & 20.34 \\
\hline kroa200 & 32302.35 & 33548.14 & 35078.73 & 4068.40 & 46.91 \\
\hline
\end{tabular}
MATLAB R2015b and executed on a system with
Windows 7 as an operating system.

Table 2. GA Results for 8 different TSP Instances

\begin{tabular}{|c|c|c|c|c|c|}
\hline \multirow{2}{*}{$\begin{array}{c}\text { TSP } \\
\text { Instance }\end{array}$} & \multicolumn{3}{|c|}{ Tour Length } & \multirow{2}{*}{$\begin{array}{c}\text { Iteratio } \\
\text { ns }\end{array}$} & \multirow{2}{*}{$\begin{array}{l}\text { Time } \\
\text { (Sec) }\end{array}$} \\
\hline & Best & Average & Worst & & \\
\hline burma14 & 3569.32 & 3625.37 & 3653.76 & 15.20 & 0.06 \\
\hline ulysses 22 & 7097.08 & 7196.98 & 7383.61 & 30.10 & 0.28 \\
\hline eil51 & 439.55 & 449.12 & 467.57 & 147.20 & 5.01 \\
\hline eil76 & 571.56 & 577.39 & 589.80 & 240.90 & 35.40 \\
\hline kroa100 & 22166.38 & 22706.78 & 23144.83 & 124.30 & 35.02 \\
\hline bier127 & 125958.10 & 128379.30 & 132107.20 & 101.30 & 28.70 \\
\hline kroa150 & 28089.45 & 28494.95 & 29262.93 & 68.50 & 47.93 \\
\hline kroa200 & 30330.92 & 31185.46 & 32198.42 & 93.40 & 142.15 \\
\hline
\end{tabular}

Table 3. Modified Elitist-ACO Results for 8 different TSP Instances

\begin{tabular}{|c|r|r|r|r|r|}
\hline \multirow{2}{*}{$\begin{array}{c}\text { TSP } \\
\text { Instance }\end{array}$} & \multicolumn{3}{|c|}{ Tour Length } & \multirow{2}{*}{$\begin{array}{c}\text { Iteratio } \\
\text { ns }\end{array}$} & $\begin{array}{c}\text { Time } \\
\text { (Sec) }\end{array}$ \\
\cline { 2 - 4 } burma14 & 3492.17 & 3523.03 & 3584.03 & 12.00 & 0.03 \\
\hline ulysses22 & 6993.08 & 7119.28 & 7222.63 & 14.40 & 0.08 \\
\hline eil51 & 429.48 & 442.09 & 450.34 & 18.60 & 0.64 \\
\hline eil76 & 549.17 & 560.05 & 575.62 & 21.70 & 1.84 \\
\hline kroa100 & 21794.41 & 22382.56 & 22929.07 & 24.30 & 3.90 \\
\hline bier127 & 121372.10 & 123031.10 & 124467.30 & 29.40 & 8.13 \\
\hline kroa150 & 27436.48 & 28253.22 & 29352.55 & 26.60 & 11.37 \\
\hline kroa200 & 30563.38 & 31102.27 & 31753.81 & 31.60 & 27.89 \\
\hline
\end{tabular}

Table 4. Symmetric RFD Results for 8 different TSP Instances

Table 5. Improved FA Results for 8 different TSP Instances

\begin{tabular}{|c|r|r|r|r|r|}
\hline \multirow{2}{*}{$\begin{array}{c}\text { TSP } \\
\text { Instance }\end{array}$} & \multicolumn{3}{|c|}{ Tour Length } & \multirow{2}{*}{$\begin{array}{c}\text { Iteratio } \\
\text { ns }\end{array}$} & $\begin{array}{c}\text { Time } \\
\text { (Sec) }\end{array}$ \\
\cline { 2 - 4 } burma14 & 3462.30 & 3474.92 & 3527.95 & 23.70 & 0.06 \\
\hline ulysses22 & 6993.08 & 7047.63 & 7110.34 & 43.10 & 0.12 \\
\hline eil51 & 433.54 & 443.27 & 450.09 & 95.90 & 0.41 \\
\hline eil76 & 558.37 & 569.61 & 583.45 & 141.40 & 1.80 \\
\hline kroa100 & 21456.26 & 21876.10 & 22608.27 & 180.50 & 5.14 \\
\hline bier127 & 120479.80 & 123247.40 & 128880.00 & 222.10 & 9.79 \\
\hline kroa150 & 28077.07 & 28268.49 & 28588.13 & 226.20 & 18.09 \\
\hline kroa200 & 29630.90 & 30159.03 & 30769.78 & 272.60 & 51.97 \\
\hline
\end{tabular}


The following tables 2 to 6 represent results for various algorithms such as GA, eACO, sRFD, iFA and CS respectively. Each of these tables shows best, average \& worst tour lengths, average iterations \& average time required over 10 different runs for each of the 8 different TSP instances.

Table 6. CS Results for 8 different TSP Instances

\begin{tabular}{|c|c|c|c|c|c|}
\hline \multirow{2}{*}{$\begin{array}{c}\text { TSP } \\
\text { Instance }\end{array}$} & \multicolumn{3}{|c|}{ Tour Length } & \multirow{2}{*}{$\begin{array}{c}\text { Iteratio } \\
\text { ns }\end{array}$} & \multirow{2}{*}{$\begin{array}{l}\text { Time } \\
\text { (Sec) }\end{array}$} \\
\hline & Best & Average & Worst & & \\
\hline burma14 & 3462.30 & 3515.59 & 3642.32 & 22.50 & 0.02 \\
\hline ulysses 22 & 6993.08 & 7079.14 & 7224.24 & 67.70 & 0.08 \\
\hline eil51 & 436.13 & 443.51 & 453.62 & 115.40 & 0.65 \\
\hline eil76 & 557.01 & 570.64 & 580.25 & 135.30 & 1.73 \\
\hline kroa100 & 21294.40 & 21863.33 & 23106.86 & 223.80 & 5.09 \\
\hline bier127 & 120877.70 & 122941.20 & 126945.70 & 359.10 & 14.61 \\
\hline kroa150 & 27177.12 & 27791.13 & 28546.68 & 709.80 & 188.68 \\
\hline kroa200 & 29635.76 & 30045.30 & 30811.75 & 698.80 & 113.30 \\
\hline
\end{tabular}

The performance of algorithms has been compared using five different parameters - best tour length, perfective error, precision error, the number of iterations and time required - as discussed below.

\section{- Best Tour Length}

Table 7 represents best tour lengths obtained by different algorithms along with optimal tour length as given in [88]. Numbers in bold fonts are best results for a given TSP instance, while, numbers in italic fonts are second best results.

This table shows that modified Elitist ACO performs well when problem size is smaller. But with an increase in a number of cities, FA and CS outperform all other algorithms.

\section{- Perfective Error}

Perfective error stands for the difference between optimal tour length and best tour length obtained by an algorithm. Mathematically it can be calculated as,

$$
\frac{\text { best length-optimal length }}{\text { optimal length }} * 100
$$

Table 8 represents the perfective error. Results establish the superiority of CS over other algorithms. Also, note that negative error for the TSP instance ulysses 22 shows that our algorithms have furnished better results compared to optimal results given in [88].

Table 7. Best Tour Length for Different NCAs

\begin{tabular}{|c|c|c|c|c|c|c|}
\hline Instance & Optimal $[88]$ & GA & eACO & sRFD & iFA & CS \\
\hline burma14 & 3323.00 & $\mathbf{3 4 6 2 . 3 0}$ & 3492.17 & 3569.32 & $\mathbf{3 4 6 2 . 3 0}$ & $\mathbf{3 4 6 2 . 3 0}$ \\
\hline ulysses22 & 7013.00 & $\mathbf{6 9 9 3 . 0 8}$ & $\mathbf{6 9 9 3 . 0 8}$ & 7097.08 & $\mathbf{6 9 9 3 . 0 8}$ & $\mathbf{6 9 9 3 . 0 8}$ \\
\hline eil51 & 426.00 & 443.47 & $\mathbf{4 2 9 . 4 8}$ & 439.55 & 433.54 & 436.13 \\
\hline eil76 & 538.00 & 573.21 & $\mathbf{5 4 9 . 1 7}$ & 571.56 & 558.37 & 557.01 \\
\hline kroa100 & 21282.00 & 22123.86 & 21794.41 & 22166.38 & 21456.26 & $\mathbf{2 1 2 9 4 . 4 0}$ \\
\hline bier127 & 118282.00 & 123477.33 & 121372.14 & 125958.13 & $\mathbf{1 2 0 4 7 9 . 8 1}$ & 120877.71 \\
\hline kroa150 & 26524.00 & 28181.29 & 27436.48 & 28089.45 & 28077.07 & $\mathbf{2 7 1 7 7 . 1 2}$ \\
\hline kroa200 & 29368.00 & 32302.35 & 30563.38 & 30330.92 & $\mathbf{2 9 6 3 0 . 9 0}$ & 29635.76 \\
\hline
\end{tabular}

Table 8. Perfective Error (\%) for Different NCAs

\begin{tabular}{|c|c|c|c|c|c|}
\hline Instance & GA & eACO & SRFD & iFA & CS \\
\hline burma14 & 4.19 & 5.09 & 7.41 & 4.19 & 4.19 \\
\hline ulysses22 & -0.28 & -0.28 & 1.20 & -0.28 & -0.28 \\
\hline eil51 & 4.10 & 0.82 & 3.18 & 1.77 & 2.38 \\
\hline eil76 & 6.54 & 2.08 & 6.24 & 3.79 & 3.53 \\
\hline kroa100 & 3.96 & 2.41 & 4.16 & 0.82 & 0.06 \\
\hline bier127 & 4.39 & 2.61 & 6.49 & 1.86 & 2.19 \\
\hline kroa150 & 6.25 & 3.44 & 5.90 & 5.86 & 2.46 \\
\hline kroa200 & 9.99 & 4.07 & 3.28 & 0.90 & 0.91 \\
\hline Average & $\mathbf{4 . 8 9}$ & $\mathbf{2 . 5 3}$ & $\mathbf{4 . 7 3}$ & $\mathbf{2 . 3 6}$ & $\mathbf{1 . 9 3}$ \\
\hline
\end{tabular}

\section{- Precision Error}

Precision error reflects the failure of an algorithm in providing consistent results. It stands for the difference between best and worst tour lengths in the context of average tour length. Mathematically it can be calculated as,

$$
\frac{\text { worst length-best length }}{\text { average length }} * 100
$$

Table 9 represents the precision error. Results establish the superiority of FA over other algorithms. For this parameter, CS performs poorly even compared to ACO and RFD. 
Table 9. Precision Error (\%) for Different NCAs

\begin{tabular}{|c|c|c|c|c|c|}
\hline Instance & GA & eACO & sRFD & iFA & CS \\
\hline burma14 & 4.34 & 2.61 & 2.33 & 1.89 & 5.12 \\
\hline ulysses22 & 4.08 & 3.22 & 3.98 & 1.66 & 3.27 \\
\hline eil51 & 6.14 & 4.72 & 6.24 & 3.73 & 3.94 \\
\hline eil76 & 6.19 & 4.72 & 3.16 & 4.40 & 4.07 \\
\hline kroa100 & 13.48 & 5.07 & 4.31 & 5.27 & 8.29 \\
\hline bier127 & 9.53 & 2.52 & 4.79 & 6.82 & 4.94 \\
\hline kroa150 & 11.69 & 6.78 & 4.12 & 1.81 & 4.93 \\
\hline kroa200 & 8.28 & 3.83 & 5.99 & 3.78 & 3.91 \\
\hline Average & $\mathbf{7 . 9 7}$ & $\mathbf{4 . 1 8}$ & $\mathbf{4 . 3 7}$ & $\mathbf{3 . 6 7}$ & $\mathbf{4 . 8 1}$ \\
\hline
\end{tabular}

\section{- Number of Iterations}

Table 10 represents a number of iterations taken by each algorithm to solve the TSP. These iteration values are obtained by subtracting stagnation counter from the total iterations. For example, if stagnation counter is 100 and total iterations are 280 , then actual iterations taken to reach to the best solution are $280-100+1=181$.

These results show that required iterations increase with an increase in problem size for each of the algorithms. Also, it can be observed that modified Elitism approach helps ACO to reduce required number of iterations drastically.

Table 10. Total Number of Iterations for Different NCAs

\begin{tabular}{|c|c|c|c|c|c|}
\hline Instance & GA & eACO & sRFD & iFA & CS \\
\hline burma14 & 32.80 & 12.00 & 15.20 & 23.70 & 22.50 \\
\hline ulysses22 & 72.60 & 14.40 & 30.10 & 43.10 & 67.70 \\
\hline eil51 & 344.50 & 18.60 & 147.20 & 95.90 & 115.40 \\
\hline eil76 & 653.00 & 21.70 & 240.90 & 141.40 & 135.30 \\
\hline kroa100 & 1189.00 & 24.30 & 124.30 & 180.50 & 223.80 \\
\hline bier127 & 2448.60 & 29.40 & 101.30 & 222.10 & 359.10 \\
\hline kroa150 & 2486.70 & 26.60 & 68.50 & 226.20 & 709.80 \\
\hline kroa200 & 4068.40 & 31.60 & 93.40 & 272.60 & 698.80 \\
\hline
\end{tabular}

\section{- $\quad$ Time Required}

Table 11 represents the time required by each algorithm to solve the TSP. The required time is counted only till the best solution appears first time, avoiding the time spent for stagnation period. Required time duration increases with increase in problem size for each of the algorithms.

Results also show that modified Elitism approach helps $\mathrm{ACO}$ to reduce required time duration drastically. But if tour length is also considered as solution quality, FA is proved superior.
Table 11. Required Time Duration (in Sec) for Different NCAs

\begin{tabular}{|c|c|r|r|r|r|}
\hline Instance & \multicolumn{1}{c|}{ GA } & \multicolumn{1}{c|}{ eACO } & \multicolumn{1}{c|}{ sRFD } & \multicolumn{1}{c|}{ iFA } & \multicolumn{1}{c|}{ CS } \\
\hline burma14 & 0.11 & 0.03 & 0.06 & 0.06 & $\mathbf{0 . 0 2}$ \\
\hline ulysses22 & 0.25 & 0.08 & 0.28 & 0.12 & $\mathbf{0 . 0 8}$ \\
\hline eil51 & 1.42 & 0.64 & 5.01 & $\mathbf{0 . 4 1}$ & 0.65 \\
\hline eil76 & 3.24 & 1.84 & 35.40 & 1.80 & $\mathbf{1 . 7 3}$ \\
\hline kroa100 & 6.90 & $\mathbf{3 . 9 0}$ & 35.02 & 5.14 & 5.09 \\
\hline bier127 & 16.91 & $\mathbf{8 . 1 3}$ & 28.70 & 9.79 & 14.61 \\
\hline kroa150 & 20.34 & $\mathbf{1 1 . 3 7}$ & 47.93 & 18.09 & 188.68 \\
\hline kroa200 & 46.91 & $\mathbf{2 7 . 8 9}$ & 142.15 & 51.97 & 113.30 \\
\hline
\end{tabular}

Best tours obtained for the TSP instance kroa200 by each of our algorithms are presented graphically in figures 1 to 5 .

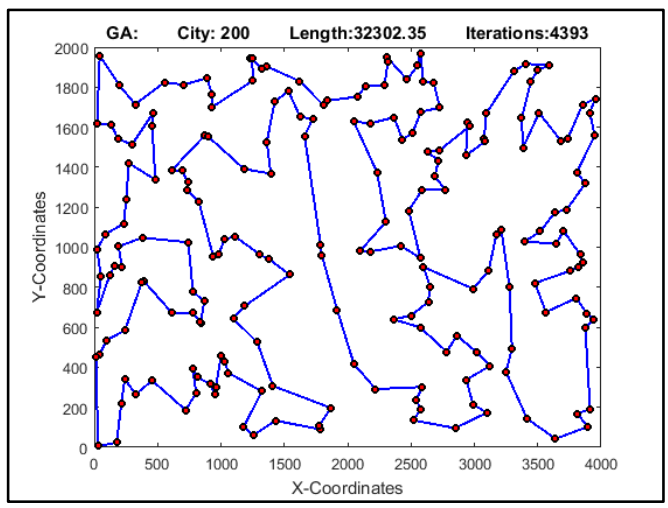

Fig.1. GA Best Tour for TSP instance Kroa200

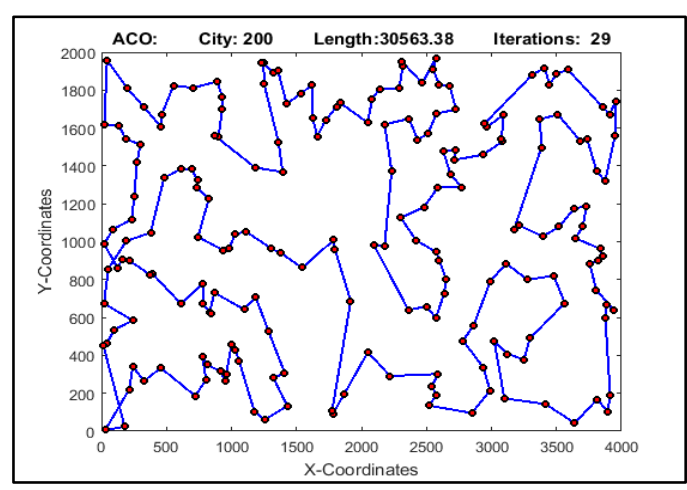

Fig.2. eACO Best Tour for TSP instance Kroa200

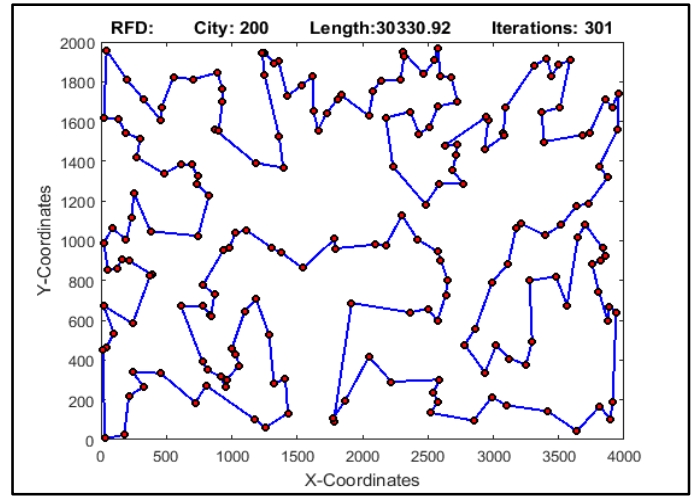

Fig.3. sRFD Best Tour for TSP instance Kroa200 


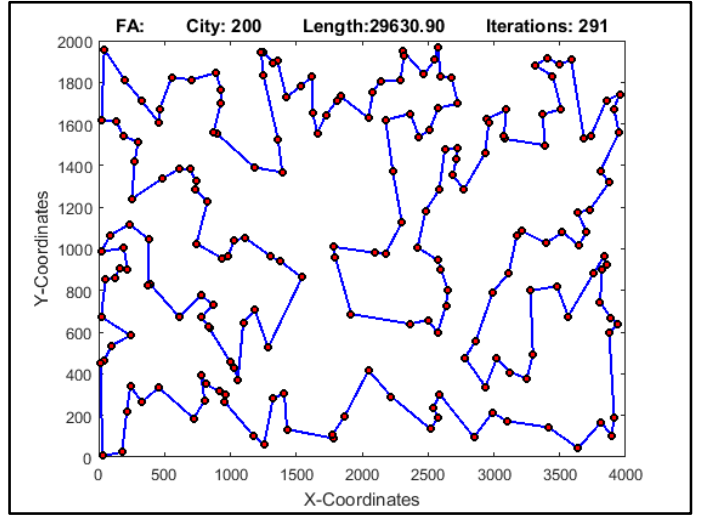

Fig.4. iFA Best Tour for TSP instance Kroa200

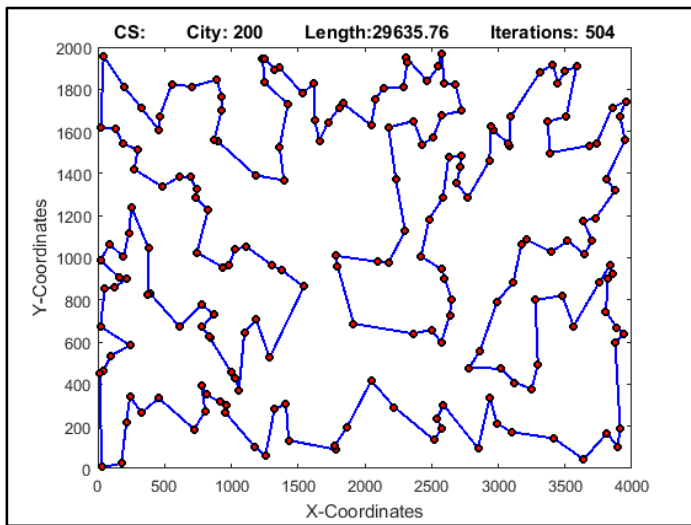

Fig.5. CS Best Tour for TSP instance Kroa200

\section{CONCLUSIONS}

This paper experimentally investigated the performance of five different natural computing algorithms. A summary of the natural computing algorithms, introduced as early in 1970 to as recently in 2016, presented. Five different algorithms - GA, ACO, RFD, FA and CS - implemented with slightly different approaches to solving TSP. GA applied tournament selection, partially matched crossover and flip as selection, crossover, and mutation operators respectively. ACO applied modified elitism approach. RFD allowed water drop to move in any direction. FA allowed top $20 \%$ fireflies to move randomly rather than single best one. CS applied real numbered sequence to represent a tour instead of permutation of integer numbers to allow arithmetic operations on solutions.

For smaller city instances all algorithms perform fairly. But with an increase in problem size, their performance degrades compared to FA and CS. Also required iterations and required time increases with increase in problem size. Modified elitist ACO is proved faster. But it fails to provide better solutions to larger problems. CS beats other algorithms with perfection but fails to provide precise results. FA takes less time to converge and provides good quality solutions irrespective of problem size in terms of best tour length, perfective error and precision error. This proves the superiority of FA over other algorithms.

\section{REFERENCES}

[1] J. Dang, A. Brabazon, D. Edelman, and M. O’Neill, "An Introduction to Natural Computing in Finance," in Applications of Evolutionary Computing, M. Giacobini, A Brabazon, S. Cagnoni, G. A. D. Caro, A. Ekárt, A. I. Esparcia-Alcázar, M. Farooq, A. Fink, and P. Machado, Eds. Springer Berlin Heidelberg, 2009, pp. 182-192.

[2] X.-S. Yang, Nature-inspired metaheuristic algorithms. Luniver press, 2010.

[3] S. Mirjalili, S. M. Mirjalili, and A. Lewis, "Grey wolf optimizer," Adv. Eng. Softw., vol. 69, pp. 46-61, 2014.

[4] D. H. Wolpert and W. G. Macready, "No free lunch theorems for optimization," Evol. Comput. IEEE Trans. On, vol. 1, no. 1, pp. 67-82, 1997.

[5] G. Reinelt, "TSPLIB-A Traveling Salesman Problem Library," ORSA J. Comput., vol. 3, no. 4, pp. 376-384, Nov. 1991.

[6] J. H. Holland, "Genetic algorithms and the optimal allocation of trials," SIAM J. Comput., vol. 2, no. 2, pp. 88-105, 1973.

[7] J. H. Holland, Adaptation in natural and artificial systems: an introductory analysis with applications to biology, control, and artificial intelligence. U Michigan Press, 1975.

[8] J. H. Holland, Adaptation in Natural and Artificial Systems. Cambridge, MA, USA: MIT Press, 1992.

[9] S. Kirkpatrick, C. D. Gelatt, and M. P. Vecchi, "Optimization by simulated annealing," SCIENCE, vol. 220, no. 4598, pp. 671-680, 1983.

[10] D. Bookstaber, Simulated Annealing for Traveling Salesman Problem. Spring, 1997.

[11] P. Moscato, On Evolution, Search, Optimization, Genetic Algorithms and Martial Arts - Towards Memetic Algorithms. 1989.

[12] A. Colorni, M. Dorigo, V. Maniezzo, and others, "Distributed optimization by ant colonies," in Proceedings of the first European conference on artificial life, 1991, vol. 142, pp. 134-142.

[13] J. R. Koza, Genetic Programming: On the Programming of Computers by Means of Natural Selection. Cambridge, MA, USA: MIT Press, 1992.

[14] J. Kennedy and R. Eberhart, "Particle swarm optimization," in , IEEE International Conference on Neural Networks, 1995. Proceedings, 1995, vol. 4, pp. 1942-1948 vol.4.

[15] R. Storn and K. Price, "Differential evolution-a simple and efficient heuristic for global optimization over continuous spaces," J. Glob. Optim., vol. 11, no. 4, pp. 341-359, 1997.

[16] N. E. Nawa and T. Furuhashi, "Fuzzy system parameters discovery by bacterial evolutionary algorithm," Fuzzy Syst. IEEE Trans. On, vol. 7, no. 5, pp. 608-616, 1999.

[17] D. DasGupta, Artificial immune systems and their applications. Springer Publishing Company, Incorporated, 2014.

[18] D. Dasgupta, Z. Ji, F. A. González, and others, “Artificial immune system (AIS) research in the last five years.," in IEEE Congress on Evolutionary Computation (1), 2003, pp. 123-130.

[19] H.-G. Beyer and H.-P. Schwefel, "Evolution strategies-A comprehensive introduction," Nat. Comput., vol. 1, no. 1, pp. 3-52, 2002.

[20] K. M. Passino, "Biomimicry of bacterial foraging for distributed optimization and control," IEEE Control Syst., vol. 22, no. 3, pp. 52-67, Jun. 2002.

[21] X. Li and J. Qian, "Studies on Artificial Fish Swarm 
Optimization Algorithm based on Decomposition and Coordination Techniques [J]," J. Circuits Syst., vol. 1, pp. $1-6,2003$.

[22] M. M. Eusuff and K. E. Lansey, "Optimization of water distribution network design using the shuffled frog leaping algorithm," J. Water Resour. Plan. Manag., vol. 129, no. 3, pp. 210-225, 2003.

[23] M. Eusuff, K. Lansey, and F. Pasha, "Shuffled frogleaping algorithm: a memetic meta-heuristic for discrete optimization," Eng. Optim., vol. 38, no. 2, pp. 129-154, 2006.

[24] X.-F. Xie and W.-J. Zhang, "Solving engineering design problems by social cognitive optimization," in Genetic and Evolutionary Computation-GECCO 2004, 2004, pp. 261-262.

[25] A. R. Mehrabian and C. Lucas, "A novel numerical optimization algorithm inspired from weed colonization," Ecol. Inform., vol. 1, no. 4, pp. 355-366, 2006.

[26] D. Karaboga, "An idea based on honey bee swarm for numerical optimization," Technical report-tr06, Erciyes university, engineering faculty, computer engineering department, 2005.

[27] D. Karaboga and B. Basturk, "A Powerful and Efficient Algorithm for Numerical Function Optimization: Artificial Bee Colony (ABC) Algorithm," J Glob. Optim., vol. 39, no. 3, pp. 459-471, Nov. 2007.

[28] S. He, Q. H. Wu, and J. R. Saunders, "A novel group search optimizer inspired by animal behavioural ecology," in Evolutionary Computation, 2006. CEC 2006. IEEE Congress on, 2006, pp. 1272-1278.

[29] R. A. Formato, "Central force optimization: a new metaheuristic with applications in applied electromagnetics," Prog. Electromagn. Res., vol. 77, pp. 425-491, 2007.

[30] R. A. Formato, "Central force optimization: a new nature inspired computational framework for multidimensional search and optimization," in Nature Inspired Cooperative Strategies for Optimization (NICSO 2007), Springer, 2008, pp. 221-238.

[31] P. Rabanal, I. Rodríguez, and F. Rubio, "Using river formation dynamics to design heuristic algorithms," in Unconventional Computation, Springer, 2007, pp. 163177.

[32] P. Rabanal, I. Rodríguez, and F. Rubio, "Applying river formation dynamics to solve NP-complete problems," in Nature-inspired algorithms for optimisation, Springer, 2009, pp. 333-368.

[33] H. Shah-Hosseini, "Problem solving by intelligent water drops," in IEEE Congress on Evolutionary Computation, 2007. CEC 2007, 2007, pp. 3226-3231.

[34] T. C. Havens, C. J. Spain, N. G. Salmon, and J. M. Keller, "Roach infestation optimization," in Swarm Intelligence Symposium, 2008. SIS 2008. IEEE, 2008, pp. 1-7.

[35] R. Zhao and W. Tang, "Monkey algorithm for global numerical optimization," J. Uncertain Syst., vol. 2, no. 3, pp. 165-176, 2008.

[36] D. Simon, "Biogeography-Based Optimization," IEEE Trans. Evol. Comput., vol. 12, no. 6, pp. 702-713, Dec. 2008.

[37] A. H. Kashan, "League championship algorithm: a new algorithm for numerical function optimization," in 2009 International Conference of Soft Computing and Pattern Recognition, 2009, pp. 43-48.

[38] K. N. Krishnanand and D. Ghose, "Glowworm swarm optimization for simultaneous capture of multiple local optima of multimodal functions," Swarm Intell., vol. 3, no. 2, pp. 87-124, 2009.
[39] Y. Marinakis, M. Marinaki, and N. Matsatsinis, "A hybrid bumble bees mating optimization-grasp algorithm for clustering," in Hybrid Artificial Intelligence Systems, Springer, 2009, pp. 549-556.

[40] R. Oftadeh and M. J. Mahjoob, "A new meta-heuristic optimization algorithm: Hunting Search," in Soft Computing, Computing with Words and Perceptions in System Analysis, Decision and Control, 2009. ICSCCW 2009. Fifth International Conference on, 2009, pp. 1-5.

[41] X.-S. Yang, "Firefly algorithms for multimodal optimization," in Stochastic algorithms: foundations and applications, Springer, 2009, pp. 169-178.

[42] X.-S. Yang, "Harmony Search as a Metaheuristic Algorithm," in Music-Inspired Harmony Search Algorithm, Z. W. Geem, Ed. Springer Berlin Heidelberg, 2009, pp. 1-14.

[43] U. Premaratne, J. Samarabandu, and T. Sidhu, "A new biologically inspired optimization algorithm," in 2009 International Conference on Industrial and Information Systems (ICIIS), 2009, pp. 279-284.

[44] E. Rashedi, H. Nezamabadi-Pour, and S. Saryazdi, "GSA: a gravitational search algorithm," Inf. Sci., vol. 179, no. 13, pp. 2232-2248, 2009.

[45] X.-S. Yang and S. Deb, "Cuckoo search via Lévy flights," in Nature \& Biologically Inspired Computing, 2009. NaBIC 2009. World Congress on, 2009, pp. 210-214.

[46] X.-S. Yang and S. Deb, "Engineering optimisation by cuckoo search," Int. J. Math. Model. Numer. Optim., vol. 1, no. 4, pp. 330-343, 2010.

[47] X.-S. Yang, "A New Metaheuristic Bat-Inspired Algorithm," in Nature Inspired Cooperative Strategies for Optimization (NICSO 2010), J. R. González, D. A. Pelta, C. Cruz, G. Terrazas, and N. Krasnogor, Eds. Springer Berlin Heidelberg, 2010, pp. 65-74.

[48] Y. Tan and Y. Zhu, "Fireworks Algorithm for Optimization," in Advances in Swarm Intelligence, Y. Tan, Y. Shi, and K. C. Tan, Eds. Springer Berlin Heidelberg, 2010, pp. 355-364.

[49] A. Salhi and E. S. Fraga, "Nature-inspired optimisation approaches and the new plant propagation algorithm," 2011.

[50] E. Cuevas, M. González, D. Zaldivar, M. Pérez-Cisneros, and G. García, "An algorithm for global optimization inspired by collective animal behavior," Discrete Dyn. Nat. Soc., vol. 2012, 2012.

[51] H. Eskandar, A. Sadollah, A. Bahreininejad, and M. Hamdi, "Water cycle algorithm-A novel metaheuristic optimization method for solving constrained engineering optimization problems," Comput. Struct., vol. 110, pp. 151-166, 2012.

[52] A. H. Gandomi and A. H. Alavi, "Krill herd: A new bioinspired optimization algorithm," Commun. Nonlinear Sci. Numer. Simul., vol. 17, no. 12, pp. 4831-4845, Dec. 2012.

[53] B. Niu and H. Wang, "Bacterial colony optimization," Discrete Dyn. Nat. Soc., vol. 2012, 2012.

[54] B. R. Rajakumar, "The Lion's Algorithm: A New NatureInspired Search Algorithm," Procedia Technol., vol. 6, pp. 126-135, 2012.

[55] M. Taherdangkoo, M. Yazdi, and M. H. Bagheri, "Stem Cells Optimization Algorithm," in Bio-Inspired Computing and Applications, D.-S. Huang, Y. Gan, P. Premaratne, and K. Han, Eds. Springer Berlin Heidelberg, 2012, pp. 394-403.

[56] M. T. M. H. Shirzadi and M. H. Bagheri, "A novel metaheuristic algorithm for numerical function optimization: blind, naked mole-rats (BNMR) algorithm," Sci. Res. Essays, vol. 7, no. 41, pp. 3566-3583, 2012. 
[57] X.-S. Yang, "Flower pollination algorithm for global optimization," in Unconventional computation and natural computation, Springer, 2012, pp. 240-249.

[58] X.-S. Yang, M. Karamanoglu, and X. He, "Flower pollination algorithm: a novel approach for multiobjective optimization," Eng. Optim., vol. 46, no. 9, pp. 1222-1237, 2014.

[59] T. Gerstner, M. Holtz, and R. Korn, "Valuation of performance-dependent options in a Black Scholes framework."

[60] A. S. Eesa, A. M. Abdulazeez, and Z. Orman, "Cuttlefish algorithm-a novel bio-inspired optimization algorithm," Int. J. Sci. Eng. Res., vol. 4, no. 9, pp. 1978-1986, 2013.

[61] A. Sadollah, A. Bahreininejad, H. Eskandar, and M. Hamdi, "Mine blast algorithm: A new population based algorithm for solving constrained engineering optimization problems," Appl. Soft Comput., vol. 13, no. 5, pp. 2592-2612, May 2013.

[62] E. Cuevas, M. Cienfuegos, D. Zaldívar, and M. PérezCisneros, "A swarm optimization algorithm inspired in the behavior of the social-spider," Expert Syst. Appl., vol. 40, no. 16, pp. 6374-6384, 2013.

[63] J. C. Bansal, H. Sharma, S. S. Jadon, and M. Clerc, "Spider monkey optimization algorithm for numerical optimization," Memetic Comput., vol. 6, no. 1, pp. 31-47, 2014.

[64] X. Li, J. Zhang, and M. Yin, "Animal migration optimization: an optimization algorithm inspired by animal migration behavior," Neural Comput. Appl., vol. 24, no. 7-8, pp. 1867-1877, 2014.

[65] A. Askarzadeh, "Bird mating optimizer: An optimization algorithm inspired by bird mating strategies," Commun. Nonlinear Sci. Numer. Simul., vol. 19, no. 4, pp. 12131228, Apr. 2014

[66] M. Ghaemi and M.-R. Feizi-Derakhshi, "Forest optimization algorithm," Expert Syst. Appl., vol. 41, no. 15 , pp. 6676-6687, 2014.

[67] B. Doğan and T. Ölmez, "A new metaheuristic for numerical function optimization: Vortex Search algorithm," Inf. Sci., vol. 293, pp. 125-145, 2015.

[68] Y.-J. Zheng, "Water wave optimization: A new natureinspired metaheuristic," Comput. Oper. Res., vol. 55, pp. 1-11, Mar. 2015

[69] S. D. Gai-Ge Wang, "Elephant Herding Optimization," 2015.

[70] A. Brabazon, W. Cui, and M. O'Neill, "The raven roosting optimisation algorithm," Soft Comput., vol. 20, no. 2, pp. 525-545, Jan. 2015.

[71] "Optimization problem," Wikipedia, the free encyclopedia. 16-Apr-2016.

[72] "Types of Optimization Problems | NEOS." [Online]. Available: http://neos-guide.org/optimization-tree. [Accessed: 15-May-2016].

[73] M. M. Flood, "The traveling-salesman problem," Oper. Res., vol. 4, no. 1, pp. 61-75, 1956.

[74] G. Gutin and A. P. Punnen, Eds., The Traveling Salesman Problem and Its Variations, vol. 12. Boston, MA: Springer US, 2007.

[75] R. Matai, S. Singh, and M. Lal, "Traveling Salesman Problem: an Overview of Applications, Formulations, and Solution Approaches," in Traveling Salesman Problem, Theory and Applications, D. Davendra, Ed. InTech, 2010.

[76] K. Sastry, D. E. Goldberg, and G. Kendall, "Genetic algorithms," in Search methodologies, Springer, 2014, pp. 93-117.
[77] N. Sureja and B. Chawda, "Random Traveling Salesman problem using Genetic Algorithms," IFRSA's Int. J. Comput., vol. 2, no. 2, 2012.

[78] M. Dorigo and T. Stützle, "Ant colony optimization: overview and recent advances," Techreport IRIDIA Univ. Libre Brux., 2009.

[79] M. Dorigo and L. M. Gambardella, "Ant colonies for the travelling salesman problem," BioSystems, vol. 43, no. 2, pp. 73-81, 1997.

[80] B. V. Chawda and N. M. Sureja, "An ACO Approach to Solve a Variant of TSP," Int. J. Adv. Res. Comput. Eng. Technol. IJARCET, vol. 1, no. 5, p. pp-222, 2012.

[81] P. Rabanal, I. Rodríguez, and F. Rubio, "Solving dynamic TSP by using river formation dynamics," in Natural Computation, 2008. ICNC'08. Fourth International Conference on, 2008, vol. 1, pp. 246-250.

[82] S. S. Shah, P. B. Swadas, and B. V. Chawda, "Travelling Salesman Problem Solutions using Various Heuristic Algorithms," in International Conference on Information, Knowledge \& Research in Engineering, Technology \& Sciences - 2012, Rajkot, Gujarat, India, 2012, pp. 1142 1145.

[83] X.-S. Yang and X. He, "Firefly algorithm: recent advances and applications," Int. J. Swarm Intell., vol. 1, no. 1, pp. 36-50, 2013.

[84] G. K. Jati and others, Evolutionary discrete firefly algorithm for travelling salesman problem. Springer, 2011.

[85] S. N. Kumbharana and G. M. Pandey, "Solving travelling salesman problem using firefly algorithm," Int. J. Res. Sci. Adv. Technol., vol. 2, no. 2, pp. 53-57, 2013.

[86] X. Ouyang, Y. Zhou, Q. Luo, and H. Chen, "A novel discrete cuckoo search algorithm for spherical traveling salesman problem," Appl. Math. Inf. Sci., vol. 7, no. 2, p. $777,2013$.

[87] W. C. E. Lim, G. Kanagaraj, and S. G. Ponnambalam, "Cuckoo search algorithm for optimization of sequence in pcb holes drilling process," in Emerging trends in science, engineering and technology, Springer, 2012, pp. 207-216.

[88] "Index of /software/TSPLIB95/tsp." [Online]. Available: http://comopt.ifi.uni-

heidelberg.de/software/TSPLIB95/tsp/. [Accessed: 20May-2016].

\section{Authors' Profiles}

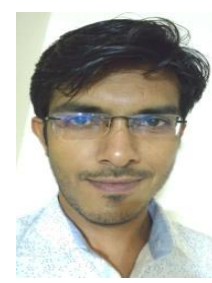

Bharat V. Chawda is a B.E. and M.E. in Computer Engineering. $\mathrm{He}$ is a GoldMedalist in M.E. from Sardar Patel University, Vallabh Vidyanagar, Gujarat, India. He is currently pursuing his Ph.D. from Gujarat Technological University, Ahmedabad, Gujarat, India. His current profile comprises of Lecturer in Department of Computer Engineering, B. \& B. Institute of Technology, Vallabh Vidyanagar. He has published books with titles Operating Systems, Database Management System, Relational Database Management System and Advanced Database Management System. He has published 8 International Journal papers and 2 Conference papers. He is a life member of The Indian Society for Technical Education and The Institutions of Engineers (India) 


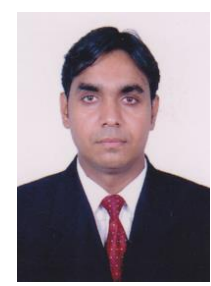

Dr. Jayesh Patel, having rich experience of 13 Years in Academics (MCA, M.Phil, Ph.D. Programme), Industry, Research, and International exposure, is holding Doctorate in ERP (Computer Science) from North Gujarat University. Rewarding his research work, he has been awarded "Career Award for Young Teachers" from AICTE, New Delhi. He is working as a recognized Ph.D. Guide at Gujarat Technological University, North Gujarat University, Ganpat University and also with many other reputed universities. He has good number of research under his name and presented more than 57 research papers in International and National Journals and Conferences. $\mathrm{He}$ has delivered number of expert talk in SANDHAN Programme and UGC Sponsored Orientation Programme. He is also the member of the board of studies and selection committees of different universities. He is also nominated by Department of Education, Govt. of Gujarat as a Coordinator at SANDHAN Program for Computer Science Subject.

How to cite this paper: Bharat V. Chawda, Jayeshkumar Madhubhai Patel,"Investigating Performance of Various Natural Computing Algorithms", International Journal of Intelligent Systems and Applications(IJISA), Vol.9, No.1, pp.46-59, 2017. DOI: $10.5815 /$ ijisa.2017.01.05 